\title{
Dissertations: A Study of the Scholar's Approach
}

\section{Joan M. Repp and Cliff Glaviano}

Four academic libraries in Ohio participated in a study exploring how and why extramural researchers access locally produced dissertations. Abstracts and indexes in hard copy were identified as the resources relied upon most heavily by all academic disciplines, with Dissertation Abstracts International and related University Microfilms International products being named most often. Researchers, regardless of discipline, were successful searching by subject more often than using any other form of access. Dissertations were most frequently requested by those writing theses, dissertations, or research papers for publication. These findings may have implications for in-house cataloging of locally produced dissertations or for institutional participation in an indexing and abstracting program.

he dissertation is a unique format for scholarly information that is not available in its original form through established professional or commercial channels. Though substantive information from the dissertation may subsequently appear in the scholarly literature as a journal article or book chapter, the original dissertation is deposited, virtually without exception, at the degree-granting institution. Although an occasional dissertation is published in its entirety, more often this follows considerable editing of style or content. Since hard copy of the dissertation is not widely disseminated, access to the information it contains becomes a concern for the scholarly community.

As Library of Congress priorities preclude cataloging of even depository copies of dissertations submitted for copyright, no LC cataloging for dissertations appears on the bibliographic utilities, and full responsibility for bibliographic control falls to the degree-granting institution. Academic libraries necessarily must either negotiate with their parent institution, or themselves originate, all policies concerning preservation, circulation, availability, shelving and degree of bibliographic control for local dissertations. Further, only the library and degree-granting institution determine the extent to which access to the dissertation is shared through an indexing service such as that provided by University Microfilms International or through contributing cataloging copy to a bibliographic utility.

Implicit in accepting responsibility for bibliographic control of the dissertation is its indexing, so that it might be readily located when needed. Presently most academic libraries provide full descriptive and subject cataloging for local dissertations and input such copy on OCLC, RLIN, or WLN. Since the dissertation format is developed by the university's graduate school, title pages are formulaic and descriptive cataloging can easily be done by a paraprofessional cataloger. Subject analysis is an altogether different matter due to the timely, experimental nature of dissertation research. It is often both difficult and time-consuming for a professional cataloger to select LC subject headings (LCSH) appropriate to these in-depth, highly specialized studies. This problem of subject analysis is most often

Joan M. Repp is Chair, Access Services and Cliff Glaviano is Principal Cataloger, University Libraries, Bowling Green State University, Bowling Green, Ohio 43403. 
noted in science and technology though works in all disciplines potentially can deal with concepts for which LCSH terms are nonexistent at the time of cataloging.

The problem of adequate classification and subject analysis is compounded by changing staffing patterns in cataloging departments. Since cataloging has been automated, the number of original catalogers has decreased. ${ }^{1}$ Each cataloger is therefore responsible for a wider group of disciplines. This reduces the probability of high subject expertise in any one of them. Coincident with the declining number of original catalogers, the number of dissertations produced has risen: doctoral degrees in the United States, for example, rose from 6,600 in 1950 to 32,700 in $1982 .^{2}$

\section{DISSERTATION USERS}

Users of dissertations can be divided into two groups: intramural scholars and extramural scholars. Comparatively little is known about either group's behavior relative to seeking and using dissertations. Informal observation from the reference desk suggests that intramural scholars writing their own theses and dissertations may use those already produced at their institution for reasons beyond obtaining scholarly information. In addition to checking bibliographies for references and determining the scope of an extant dissertation's coverage of a topic to avoid duplicating another's research, intramural scholars use local dissertations to determine a format acceptable to their institution, to evaluate research approaches that have been approved by particular dissertation committee chairs, and for other reasons not related to scholarly content.

The in-house tools for locating a dissertation written at an institution significantly exceed those available to the extramural scholar, who may be assumed to be interested in the dissertation's content alone. While the extramural scholar can be expected to use standard indexes, abstracts, and databases, the intramural scholar, provided by his library with LCSH subject analysis and potentially, additional local access by adviser name, department/major, or other approach, probably can ignore standard sources altogether for locating local dissertations.

Often libraries that do not provide full cataloging for dissertations aid the intramural scholar through separate in-house indexes or special shelving arrangements, amenities lost to the extramural scholar. Should the library provide only minimal on-campus access to local dissertations, promoting the use of standard sources, the intramural scholar can still take advantage of maintaining close contact with others in his discipline, many of whom will have good knowledge of the dissertations produced in the discipline and available at the institution.

It is reasonable to assume that information needs of the intramural and extramural scholar can differ in scope and emphasis and that the intramural scholar has resources in addition to standard sources for accessing local dissertations. Standard tools of potential use to both groups have been enhanced considerably by technology. Many institutions granting doctoral degrees participate in the Dissertation $\mathrm{Ab}$ stracts International (DAI) program, which generates indexes in both hard copy and online through commercial database services. Broad subject access is available in DAI and American Doctoral Dissertations (ADD) while LSCH access is available for those cataloged dissertations in the portion of the OCLC database available on BRS. DAI hard copy is indexed also by keyword from title and by author; ADD additionally by author and by institution. The database available on BRS and Dialog is compiled from both ADD and DAI.

In addition to searches available from the hard-copy indexes, search terms constructed from Boolean combinations of keywords from title or the entire abstract can be used on BRS and Dialog to locate relevant dissertations. Meanwhile, the technology for using the commercial databases is widely available to the scholar at the academic library: in 1980, all fortythree academic libraries responding to a survey indicated they had access to Dialog for database searching. ${ }^{3}$

While answers to the basic questions of how a patron gains access to a local disser- 
tation and how a patron uses its information can be assumed from observations by experienced reference librarians, no published research exists to affirm or deny these assumptions. Costs associated with participating in the DAI program and costs associated with original cataloging of locally produced materials should generate continuing interest in the question of how best to serve intramural and extramural scholars who seek dissertation information. Clear reasons to modify cataloging procedures to include, for example, access by thesis adviser as suggested by George Harris and Robert Huffman; reasons to support the cost of full cataloging of dissertations; and/or reasons to justify the expense of participating in a cooperative indexing program need to be determined. Assessment of patron behavior in seeking and using dissertation information becomes necessary before institutional procedures can be modified or program participation evaluated.

\section{LITERATURE SURVEY}

Little has been published in the literature on the handling, cataloging, classification, and subject analysis of locally produced theses and dissertations. The literature concerning access is dated enough to preclude mention of the commercial databases, and institutional participation patterns have changed enough since the 1970 s to make descriptions of the hard-copy indexes and their coverage quite misleading.

Julie Moore's article, "Bibliographic Control of American Doctoral Dissertations: A History," presents a brief historical summary of "national listings of dissertations which are a unique alternative to the control of published and unpublished dissertations in the United States and Canada.'"4 The same topic, discussed from a slightly different perspective and with considerable perspicacity, may be found in Donald Davinson's Theses and Dissertations as Information Sources. ${ }^{5}$ The second part of Moore's work, "Bibliographic Control of Doctoral Dissertations: An Analysis," focuses on a comparison of the usefulness and limitations of American Doctoral Dissertations and Dissertation Abstracts. She also found that only
2.1 percent of the dissertations she studied were published as books, an additional 1.4 percent could be identified as parts of a book, and that 15.2 percent were published as journal articles after heavy rewriting. ${ }^{6}$

Calvin Boyer's work, The Doctoral Dissertation as an Information Source, itself originally a dissertation, assessed the extent to which dissertations in selected sciences produced between 1963 and 1967 served as information sources by studying citations and dissertation-based publications. ${ }^{7}$ Kelly Patterson and others, in "Thesis Handling in University Libraries," reported the results of a survey of ninety universities granting doctoral degrees to determine local practice in "binding, cataloging, classification, storage and checking of format practices" with the intent of recommending processing practices. ${ }^{8}$ Lois M. Pauch's "Thesis/ Dissertation Processing and OCLC" details the impact of OCLC on cataloging procedures for theses and dissertations at the University of Illinois at UrbanaChampaign, speeding the process from three hours to one-half hour.

Most recently, George Harris and Robert Huffman completed a study of cataloging, classification, and subject analysis of locally produced dissertations. "Cataloging of Theses: A Survey" summarizes their findings. In addition to surveying actual practices for dissertation cataloging in academic libraries, in effect what currently is done to serve the needs of intramural scholars and reference librarians, they found that without AACR2 rules specific to dissertations and the guidance of LC cataloging "libraries are forced to improvise." 10

Though the literature is informative regarding current practice in the local bibliographic control of dissertation information and its sharing on the bibliographic utilities, studies exploring the content of the various dissertation indexes, abstracts and databases, and the use of dissertation information within the scholarly community are so outdated as to be extremely misleading.

\section{PURPOSE OF THE STUDY}

The purpose of this study is to assist in 
the evaluation of current cataloging practices as applied to dissertations produced in-house at four academic libraries in Ohio. The study is limited to exploring the behavior of the extramural scholar and attempts to identify user by type of institutional affiliation; purpose for which the dissertation was used; and what tools and approaches were successfully used in identifying and locating the dissertation.

\section{Hypotheses}

1. Scholars access dissertations as an aid to writing dissertations.

2. Due to the research orientation of the parent institution, more borrowing of dissertations is done through Association of Research Libraries than other types of libraries.

3. As a generalization, the dissertations requested are newer by date than older but this behavior varies measurably between social scientists, hard scientists, and scholars in the humanities.

4. The major access is through Dissertation Abstracts International, its related precursors and products.

5. Subject access is least often used to locate a relevant dissertation since subject control of dissertation information is very limited.

\section{Assumptions}

1. Interlibrary loan usage is an accurate representation of extramural use.

2. The behavior of the extramural scholar differs significantly from that of the intramural scholar.

3. The dissertations of the participating institutions available through OCLC, indexes, and databases accurately represent all of each institution's locally produced dissertations.

\section{Methodology}

Four academic libraries in Ohio participated in this study: Ohio State University, University of Cincinnati, University of Toledo, and Bowling Green State University.

A census was taken of all dissertations borrowed through the interlibrary loan departments of the cooperating institutions for a period of one year.

A questionnaire was mailed out with each dissertation and a record was maintained in-house listing the borrowing institution, the subject of the dissertation as identified in the dissertation or by the department supervising the dissertation, discipline of the dissertation, and date on the title page. The borrower was requested to return the completed questionnaire with the dissertation. There was no follow-up. The data gathering covered a twelve-month period from July 1, 1983, to June 30, 1984.

\section{Characteristics of the Institutions Selected}

The four institutions selected represented a mix of academic programs leading to the doctorate and represented medium-sized and large universities. The institutions shared the following characteristics. All four

1. fully cataloged their dissertations according to national standards;

2. entered their cataloging record in a national bibliographic database, in this case, OCLC;

3. participated in the Dissertation Abstracts International program;

4. permitted dissertations to circulate through interlibrary loan (ILL).

There are some variations among the institutions in the following areas:

1. Each began entering records in OCLC at different times (earliest, 1972; most recent, 1978).

2. Participation in Dissertation $\mathrm{Ab}$ stracts International varied from institution to institution (earliest, 1954; most recent, 1973) and by discipline within institutions.

3. One institution limited loans of dissertations produced after 1954 to reciprocating institutions only, since these dissertations are available through University Microfilms International.

4. Charging practices for ILL varied widely and included no charge, postage only, $\$ 4.50$ flat rate, or reciprocal charging.

5. Two institutions would not lend dissertations to high school libraries. There werc no other restrictions on lending.

\section{RESULTS}

In all, 542 questionnaires were sent out with the dissertations as they were circu- 
lated through ILL. Of these, 269 were returned for an overall return rate of $49.6 \%$. The percentage base of several subpopulations was high enough to be reliable. Results were treated with SPSS statistical package. Table 1 summarizes the number of questionnaires sent and returned by institution.

The borrowing institutions were categorized as holding membership in the Association of Research Libraries (Bowker Annual, 1982); non-ARL university libraries; college libraries; other institutions of higher education including junior and community colleges, technical and trade schools; public libraries; governmental corporate libraries; business corporate libraries; other corporate libraries including museum and hospital libraries; and high school libraries.

Institutions of higher education accounted for $93.2 \%$ of the loans, corporate libraries $5.1 \%$, and public libraries $2.2 \%$. One dissertation was loaned to a high school library. As can be seen in table 2, the most frequent borrowers were ARL member libraries.

The number and percentage of dissertations borrowed by discipline is reflected in table 3. Of the dissertations borrowed, the highest number, 235 (43.4\%), were bor- rowed in academic disciplines from the social sciences. Of the social science loans, $176(75 \%)$ dealt with education, excluding educational psychology. The results were highly institution dependent. No attempt was made to relate program offerings and number of degrees granted in each discipline to the observed frequency of borrowing of the discipline.

Table 4 compares the vintage and discipline of the dissertations borrowed. The currency of the dissertations borrowed ranged widely from 1906 through 1983, and some variation among the disciplines relative to the recency of dissertations borrowed is apparent.

The data support the assumption that recently produced dissertations are more heavily used than those written earlier. Figures produced at the same rate for the remainder of the 1980 s would result in an $N$ of 395 borrowings for the decade. The figures of table 4 must be interpreted with some caution, however, since a number of pertinent factors are unknown, including the number of dissertations produced by the cooperating institutions in each discipline for each time period. Certainly the trend would be upward for total numbers produced at the four institutions, though program emphasis would result in skew-

TABLE 1

RESPONSES BY INSTITUTION

\begin{tabular}{lcccc}
\hline \hline & $\begin{array}{c}\text { Number } \\
\text { Sent }\end{array}$ & $\begin{array}{c}\text { Number } \\
\text { Returned }\end{array}$ & \% Returned & $\begin{array}{c}\text { \% of Total } \\
\text { Returned }\end{array}$ \\
\hline University of Toledo & 49 & 31 & 63 & 11.5 \\
Bowling Green State University & 84 & 61 & 73 & 22.7 \\
University of Cincinnati & 121 & 59 & 49 & 21.9 \\
Ohio State University & 288 & 118 & 41 & 43.8 \\
Total & 542 & 269 & N/M & $99.9^{*}$ \\
\hline
\end{tabular}

*Total less than $100 \%$ due to rounding.

TABLE 2

BORROWERS BY TYPE OF INSTITUTION

\begin{tabular}{lcr}
\hline \hline Type of Institution & Number Loaned & \% of Total \\
\hline Member of ARL & 291 & 53.7 \\
Other University & 181 & 33.4 \\
College (4 year) & 20 & 3.7 \\
Other Institution of & 12 & 2.2 \\
Higher Education & 28 & 5.1 \\
Corporate Libraries & 9 & 1.7 \\
Other & 541 & $99.8^{*}$ \\
Total & & B \\
\hline
\end{tabular}

*Total less than $100 \%$ due to rounding. 
TABLE 3

BORROWING BY DISCIPLINE

\begin{tabular}{lcc}
\hline \hline Discipline of Dissertation & Number & Percent \\
\hline Social Science & 235 & 43.4 \\
Applied Science/Technology & 98 & 18.1 \\
Languages/Literature & 65 & 12.0 \\
History & 40 & 7.4 \\
Business & 38 & 7.0 \\
Arts & 26 & 4.8 \\
Pure Sciences & 24 & 4.4 \\
Philosophy & 10 & 1.8 \\
Health Sciences & 4 & .7 \\
Religion & 1 & .2 \\
Total & 541 & $99.8^{\star}$ \\
\hline
\end{tabular}

'Total less than $100 \%$ due to rounding.

TABLE 4

NUMBER OF DISSERTATIONS BORROWED BY DISCIPLINE/DATE

\begin{tabular}{lcccccr}
\hline \hline Discipline & $1906-49$ & $1950-59$ & $1960-69$ & $1970-79$ & $1980-83$ & Total \\
\hline Applied Science/Technology & 3 & 4 & 10 & 55 & 26 & 98 \\
Arts & 1 & 5 & 4 & 9 & 7 & 26 \\
Business & 2 & 2 & 2 & 16 & 15 & 37 \\
History & 10 & 3 & 2 & 21 & 4 & 40 \\
Languages/Literature & 3 & 3 & 8 & 39 & 12 & 65 \\
Health Sciences & 0 & 0 & 0 & 3 & 1 & 4 \\
Philosophy & 1 & 1 & 2 & 2 & 4 & 10 \\
Pure Sciences & 5 & 3 & 3 & 9 & 4 & 24 \\
Religion & 0 & 0 & 1 & 0 & 0 & 1 \\
Social Sciences & 9 & 10 & 17 & 115 & 84 & 235 \\
Total & 34 & 31 & 49 & 269 & 157 & 540 \\
\hline
\end{tabular}

ing of figures for popular courses of study and possibly a decline in number of dissertations produced in less popular disciplines over time.

Another factor difficult to assess accurately from the data is the influence of indexes on the findings. Indexes and abstracts, most particularly Dissertation Abstracts International (including its precursors and related products) are the tools most heavily relied upon by extramural scholars, yet these tools are neither as comprehensive nor as complete as one would wish.

Scholars were asked to identify the purpose for which the dissertation would be used, or, in other words, to identify the anticipated end product of their research. Of extramural users, $57 \%$ indicated use in relation to the borrower's own dissertation or thesis; $30 \%$, use for an academic paper or publishable research project other than a thesis or dissertation; $8.3 \%$, use in solving a research problem for which publication was not anticipated; while other uses accounted for the remaining $4.7 \%$. Respondents indicated that $90 \%$ of their anticipated products would be associated with an institution of higher education, the remaining $10 \%$ in government or business and industry.

Overall, scholars indicated that they were borrowing a dissertation in the same academic discipline as their work in progress $69 \%$ of the time. Borrowers from social sciences, history, and languages/literature borrowed dissertations in their academic discipline at a rate of $80 \%$ or greater.

In addition to indicating the purpose for which the dissertation was being requested, the borrowers were asked to name the tools they had used to identify and locate the dissertation, as well as their approach to the particular tools.

Table 5 reflects the resource used by type of borrowing institution. Resources borrowers used most often in locating dis- 
TABLE 5

GENERAL CATEGORY OF RESOURCE USED BY TYPE OF BORROWING INSTITUTION

\begin{tabular}{|c|c|c|c|c|c|c|c|c|c|c|c|c|}
\hline \multirow[b]{2}{*}{ Resource } & \multicolumn{12}{|c|}{ Type of Institution } \\
\hline & \multicolumn{2}{|c|}{ ARL } & \multicolumn{2}{|c|}{ Other Univ. } & \multicolumn{2}{|c|}{ H Higher Ed. } & \multicolumn{2}{|c|}{ Corporate } & \multicolumn{2}{|c|}{ Other } & \multicolumn{2}{|c|}{ Total } \\
\hline Index/Abstract & 80 & 57.8 & 38 & 44.2 & 7 & 38.9 & 3 & 18.8 & 1 & 25 & 129 & 49.0 \\
\hline Newsletter & 21 & 15.1 & 16 & 18.6 & 6 & 33.3 & 8 & 50.0 & 2 & 50.8 & 53 & 20.2 \\
\hline Automated Database & 31 & 22.3 & 29 & 33.7 & 5 & 27.8 & 3 & 18.7 & 0 & 0 & 68 & 25.9 \\
\hline Word of Mouth & 7 & 5.0 & 3 & 3.5 & 0 & 0 & 2 & 12.5 & 1 & 25 & 13 & 4.9 \\
\hline Total & 139 & 100 & 86 & 100 & 18 & 100 & 16 & 100 & 4 & 100 & 263 & 100 \\
\hline
\end{tabular}

sertation information were printed indexes and abstracts followed by automated databases. As a group, non-ARL university libraries show the highest rate of database searches at $33.7 \%$. The remaining non-ARL institutions searched automated databases at rate of $27.8 \%$. Though both categories of institutions exceeded the rate of database searching in ARL libraries (22.3\%), the variation from chance distribution was not significant using a chi-square test.

The scholar's approach to finding dissertation information appears to depend in part on the academic discipline of the borrower. The categories of resources used by those scholars identifying their disciplines as applied science/technology, languages/literature, the arts, or the social sciences are tabulated in table 6 . These disciplines accounted for $80 \%$ of the total responses and the remainder appeared too scattered to yield meaningful results.

Borrowers in these categories relied more heavily on printed indexes and abstracts than on any other form of access surveyed. Other printed sources, such as newsletters, books, and journal articles were identified as chief finding tools ranging from a rate of $32 \%$ for applied sciencel technology to a low of $8.6 \%$ for social sciences of the total number of responses in the respective discipline. Social scientists indicated using automated databases at a rate second only to their use of indexes and abstracts, while other disciplines mentioned database use at a much lower rate. In fact, scholars from the arts identified word-of-mouth sources more often than automated databases, but not at a rate that the chi-square test showed as significant.

A chi-square test of table 6 data indicated variations significant at the .05 level in the source choices of borrowers from applied science/technology and the social sciences, the former group relying on nonindex printed sources more heavily than could be expected, and the latter on using automated databases. The significant and near-significant (arts use of word of mouth) results clearly indicate disciplinespecific influences on borrowers' use of sources. Though no data were gathered, the influences may include the availability of specialized indexes in certain disci-

TABLE 6

GENERAL CATEGORY OF RESOURCE USED BY SELECTED DISCIPLINE

\begin{tabular}{|c|c|c|c|c|c|c|c|c|c|c|}
\hline \multirow[b]{2}{*}{ Resource } & \multicolumn{2}{|c|}{$\begin{array}{l}\text { Applied } \\
\text { Sciencel } \\
\text { Technology }\end{array}$} & \multirow{2}{*}{\multicolumn{2}{|c|}{ Arts }} & & $\begin{array}{l}\text { pline } \\
\text { ages/ } \\
\text { ture }\end{array}$ & \multicolumn{2}{|c|}{$\begin{array}{c}\text { Social } \\
\text { Sciences }\end{array}$} & \multicolumn{2}{|c|}{ Total } \\
\hline & $\mathrm{N}$ & $\%$ & & & $\mathrm{~N}$ & $\%$ & $\mathrm{~N}$ & $\%$ & $\mathrm{~N}$ & $\%$ \\
\hline Index/Abstract & 22 & 44.0 & 14 & 60.9 & 21 & 65.6 & 53 & 51.0 & 110 & 52.6 \\
\hline Newsletter, & 16 & 32.0 & 1 & 4.3 & 6 & 18.8 & 9 & 8.6 & 32 & 15.3 \\
\hline Automated Database & 9 & 18.0 & 3 & 13.0 & 5 & 15.6 & 40 & 38.5 & 57 & 27.3 \\
\hline Word of Mouth & 3 & 6.0 & 5 & 21.8 & 0 & 0.0 & 2 & 1.9 & 10 & 4.8 \\
\hline Total & 50 & 100 & 23 & 100 & 32 & 100 & 104 & 100 & 209 & 100 \\
\hline
\end{tabular}


plines or that scholars in certain disciplines are more sophisticated in using automated databases either specific or germane to their area of study. Certainly the quality and availability of databases in a discipline influence the scholar's willingness to search them, while both the nature of the discipline and the nature of dissertation information probably influenced all search behaviors. For example, the need for timeliness in applied science/ technology may induce its scholars to use the discipline's journal/newsletter network more diligently than scholars use similar resources in other fields. Further speculation suggests that the experimental nature of dissertation research may lead to dissertations being cited more often in the literature of applied science/ technology, thus making printed sources more valuable to the discipline. Similarly, the performance nature of some music and fine-arts dissertations may result in deficient or nonexistent abstracts and perhaps a higher incidence of nondescriptive titles, leading borrowers from the arts to rely more heavily on word of mouth as an appropriate approach to such information.

A closer examination of three or four broad categories of searching resources (the number of word-of-mouth responses being quite low) is of some interest. Of total responses, the chief source of information was designated as "index/abstract" 135 times. Of this number, Dissertation Abstracts International and Comprehensive Dissertation Index accounted for 99 and 21 responses respectively, or $89 \%$ of all indexes and abstracts used. While specialized indexes and abstracts accounted for the remaining $11 \%$ reported, the only other titles reported more than once were MLA Annual Bibliography, Music Index, and Agricultural Education, each cited twice.

Borrowers reporting use of nonindex print sources to locate dissertations found information in subject bibliographies $30 \%$ of the time. Professional newsletters accounted for $28 \%$, separately published monographs $27 \%$, and journals $15 \%$ of the print sources.

Of all responses, only $22 \%$ indicated finding dissertation information by database searching, a lower rate than the $27.3 \%$ indicated for the selected disciplines of table 6 . Some $86 \%$ did not search the database themselves but had searches performed by third parties. All those who did their own searches were from nonARL university libraries. Borrowers from the social sciences performed $70.2 \%$ of all database searches, their 40 searches accounting for $38.5 \%$ of all searches in the social sciences. Responses to questions relating to use of specific databases and search terms used did not yield useful results. The majority of respondents either did not know the name of the database searched for them by an intermediary or supplied the acronym of the local inhouse database. Though several indicated they had accessed Dissertation Abstracts Online, there were no clear trends or implications for using it or any other database named.

\section{TERMS USED TO ACCESS DISSERTATIONS}

Scholars were asked to indicate the term by which they located the material borrowed regardless of the tools they used for access. In examining the responses it becomes apparent that some confusion existed concerning the differences among subject, academic discipline, and search term used to access the dissertation. Responses received indicated successful searching by subject $53.1 \%$, by search term $8.9 \%$, by browsing $5.4 \%$, by academic discipline $4.3 \%$, and by other means $.8 \%$ of the time. Although search term was intended to convey the concept of nonauthor, -title, or -subject searching, such as searching by keyword from title, perhaps combined with subject and/or discipline phrases or dates using Boolean logical operators; it is unclear whether extramural scholars responding made much distinction between subject, search term, or academic discipline in categorizing the terminology by which they located dissertations.

As large numbers of respondents (44.6\% of overall returns) list DAI or CDI as their chief source of information, it becomes necessary to investigate the termi- 
nology used in these indexes. In both, groups are arranged by broad subject terms equivalent or nearly equivalent to academic disciplines (e.g., agriculture; biology; chemistry, organic; ecology; microbiology, etc.), which are then subarranged by keyword from title of the dissertation that often appears to be the subject of the work. In fact, prefatory material in CDI calls such a keyword from title the "subject keyword.'

\section{CONCLUSIONS}

Based on the initial hypotheses, the following conclusions can be drawn:

1. Most extramural scholars use dissertation information to produce other scholarly and theoretical works such as dissertations, theses, or research papers, rather than applied works. As some dissertations are published later in whole or in part, it cannot be assumed that dissertations have only theoretical rather than practical applications, however.

2. Though research libraries as identified by ARL membership borrowed the majority of all dissertations loaned during the project, other university libraries also accounted for a substantial number of loans.

3. Overall, more recent dissertations were requested than older works, and, although there were variations among the disciplines, the data will not support discipline-specific trends concerning the need for timely dissertation materials. Closer examination of the history of the granting of U.S. doctoral degrees leads to the realization that since 1920 more than half were granted from 1971 to 1983 . It may be premature to speculate as to whether scholars actually consider the recency of dissertation information as they choose a search tool or whether any discipline can establish a preference for recent dissertation material given the extremely skewed distribution of dissertations produced.

4. Access was achieved more often through indexes and abstracts than any other source, in fact, more than all other sources combined. Dissertation Abstracts and its related products were the most heavily used tools within the category de- spite limitations such as their lack of completeness in certain institutional holdings, and employment of broad, authorassigned subject categories.

5. Extramural scholars most commonly approach dissertation information by subject. It is somewhat perplexing to realize that most scholars found their information by using subject terms that mimic the names of academic disciplines and that are often less descriptive than keywords from the dissertation's title.

\section{DISCUSSION AND SUMMARY}

Though it is clear that the majority of extramural scholars employ dissertation information in formulating theses, dissertations, or academic research projects, there is no obvious indication of how such information is employed. Specifically, there is considerable difference between the borrower's use of a dissertation in ensuring that a project will not duplicate earlier work and use of dissertation data/results/ arguments for comparison or contrast with the borrower's own ideas. Presumably, the majority of extramural scholars use dissertation information for comparison or contrast since these borrowers will have read the abstracts of relevant dissertations before requesting them on ILL, borrowing dissertations most similar to their own research in relatively rare instances in order to determine that a particular aspect of the topic has been fully exhausted.

Even though access to dissertations is self-selected by the degree-granting institution through the amount of cataloging input in the utilities and the extent of participation in indexing services, there is an audience for dissertation information outside research and university libraries. Although access is limited by indexing services promoted and designed to serve higher education and cataloging data shared chiefly with other academic institutions, a portion of that audience still seeks dissertation information.

To follow another line of thought, assume that dissertations per se are of interest only to other scholars writing their dissertations and that the process is an 
exercise in "how to do" research. This position has been supported by Bernard Berelson's research in which graduate faculty were asked whether the dissertation was an original contribution to knowledge or an exercise in research training. More than $50 \%$ responded that it is primarily research training; only $15 \%$ responded that it is primarily a contribution to knowledge.

Assuming that authors of dissertations containing significant contributions to human knowledge will disseminate this information in another form, such as a monograph or as a journal article, perhaps the dissertation needs no wider dissemination than it has at present, and needs only minimal bibliographic control. Nevertheless, some bibliographic control, including only access by author, title, and institution, would be necessary for those dissertations produced as exercises in research and for those cases in which authors may not realize the potential impact of their research.

Indications are that if dissertation content remains of value due to unique qualities of dissertation research and its rigorous methodology (something Davinson and Boyer both commented on in their works), then libraries might expect more interest in the dissertation from outside academia, especially as database searching becomes increasingly available to business. Trends in higher education would also indicate potential increased use of dissertations outside academia as the number of Ph.D.'s working outside higher education increases. Though the survey was unable to gauge changes in use patterns by categories of borrowers and only surveyed use by ILL of the four libraries' collections, there is some feeling of increased use outside academia, especially since so many dissertations are available at reasonable prices through University Microfilms International (UMI).

UMI products have a tremendous influence on the availability of dissertation access and consequently on all those seeking dissertation information. Dissertation $\mathrm{Ab}$ stracts International (DAI), Comprehensive Dissertation Index (CDI), and Ameri- can Doctoral Dissertations (ADD) appear to be the most comprehensive hard-copy tools available to extramural scholars. The popularity of DAI and CAI over specialized indexes in the survey certainly invites speculation that extramural scholars prefer comprehensive coverage to the more focused approach offered in the specialized indexes. Unfortunately, the UMI indexes, hence the database, are incomplete.

Of potential significance, participation in the UMI indexing programs may lead to decisions against the ILL loaning of dissertations by participants who may suggest that prospective borrowers obtain such materials from UMI. Considering such possible restriction on ILL borrowing, it may be necessary for future investigations into the use of dissertation information to consider UMI order files as more indicative of demand for and use of dissertations than ILL borrowing. If, in the future, relatively few academic libraries allow unrestricted borrowing of dissertations included in the DAI program, UMI may be the only good source of information on scholarly demand for dissertations.

Though the responsibility for providing subject access, as with providing for dissertation bibliographic control, falls to libraries at the degree-granting institutions, these libraries may be well advised to examine policies that prescribe LCSH subject analysis for dissertation cataloging, especially if they participate in the DAI program. Though it may seem an abdication of responsibility to leave subject analysis to commercial indexers or dissertation authors, applying subject analysis at the time of cataloging is of extremely limited value to the extramural scholar.

It does not appear certain that including subject access with dissertation cataloging input on the utilities is of sufficient merit to justify its expense relative to its availability. Since only a portion of OCLC is available on BRS, only a sampling of LCSH access is available to dissertations nationwide. The chief benefit of including subject analysis at time of cataloging is still to the intramural scholar, arguably a good investment in providing service to local clientele through manual or online public 
catalogs, even though these same researchers would be expected to behave much as the survey respondents when extending their inquiries to the external scholarly community.

As subject access to the OCLC database expands under a configuration expected to be in place by 1988 , there may be greater reason for providing subject analysis in input cataloging for locally produced materials. On the other hand, as more searching hardware and software, more subject databases and offline databases on CDROM become available to potential end users, researchers may begin to make less use of the subject approach to dissertation information and make better use of the capabilities of keyword searching whether in the UMI database or a discipline specific database.

Because the literature amply supports the superiority of Boolean combinations of keyword search terms over the use of standardized subject headings in the context of the online environment, the question of whether or not to continue subject analysis in cataloging these materials, for potential use by other members of a bibliographic utility or potential use in the academic library public catalog, may yet be moot.

\section{SUGGESTIONS FOR FURTHER RESEARCH}

It should be apparent from the discussion of this study that there are many topics related to, or concerned with, the iocation and use of dissertation information that are worthy of further study. Among the greatest needs:

1. Further in-depth study of the manifestations of dissertation information, dissertations and their derivations, in the scholarly community. Existing studies are quite dated, and even narrow, disciplinespecific treatment on use would be very helpful.

2. A closer exploration of the relationship, if any, between particular disciplines and the recency of dissertation information. This could take dissertation-derived manifestations into account.

3. Examination of whether or not the use of dissertation information is increasing outside academia.

4. A study of how anticipated use of dissertation information might influence the choice of tools or choice of search term in locating relevant information.

5. Exploration of the relationship between the choice of search tools and a discipline: determining which factors contribute to furthering effective research methods concerning dissertation information; discovering which methods of training and promotion might be furthered by library involvement.

6. Full study of the content and coverage of various general dissertation indexes with the intent of determining their reliability in providing full availability of dissertation information to respective disciplines, perhaps with the aim of conveying any discovered gaps to the scholarly community and suggesting more comprehensive resources available beyond a given hard-copy index.

\section{REFERENCES AND NOTES}

1. Peter Spyers-Duran, "The Effects of Automation on Organizational Change, Staffing, and Human Relations in Catalog Departments" in Requiem for the Card Catalog ed. Daniel Gore, Joseph Kimbrough and Peter Spyers-Duran (Westport, Conn.: Greenwood, 1979), p.36.

2. U.S. Bureau of the Census, Statistical Abstract of the United States (Washington: U.S. Govt. Pr. Off., 1985), p.157.

3. Connie Lamb, "Searching in Academia" Online 5:80 (Apr. 1981).

4. Julie Moore, "Bibliographic Control of American Doctoral Dissertations: A History," Special Libraries 63:227-30 (May/June 1972).

5. Donald Davinson, Theses and Dissertations as Information Sources (Hamden, Conn.: Linnet, 1977), p.44-47. 
6. Julie Moore, "Bibliographic Control of American Doctoral Dissertations: An Analysis," Special Libraries 63:289 (July 1972).

7. Calvin James Boyer, The Doctoral Dissertation as an Information Source: A Study of Scientific Information Flow (Metuchen, N.J.: Scarecrow, 1973), p.23.

8. Kelly Patterson, Carol White, and Martha Whittacker, "Thesis Handling in University Libraries," Library Resources \& Technical Services 21:274-85 (Summer 1977).

9. Lois M. Pausch, "Thesis/Dissertation Processing and OCLC," Research Libraries in OCLC: A Quarterly 4:1-4 (Oct. 1981).

10. George Harris and Robert Huffman, "Cataloging of Theses: A Survey," Cataloging and Classification Quarterly 5:no.4:1 (Summer 1985).

11. Bernard Berelson, Graduate Education in the United States (New York: McGraw-Hill, 1960), p.174. 